\title{
PERMAINAN ANAK-ANAK DI KECAMATAN CONGGEANG KABUPATEN SUMEDANG (Kajian Struktural dan Etnopedagogik)
}

\author{
Muhamad Yogi Hamdani \\ SMP Negeri 30 Bandung \\ Pos-el: yogihamdan@gmail.com
}

\begin{abstract}
Abstrak
Penelitian ini membahas permainan anak-anak yang berada di Kecamatan Conggeang Kabupaten Sumedang dari segi struktural dan etnopedagogik. Latar belakang penelitian ini adalah keadaan permainan anak-anak sekarang yang sudah mulai ditinggalkan karena tergerus oleh permainan-permainan modern. Metode yang dipakai dalam penelitian ini adalah metode deskriptif. Teknik yang dipakai untuk mengumpulkan data dalam penelitian ini adalah observasi, wawancara, studi pustaka, dan dokumentasi. Dari hasil penelitian ditemukan 28 permainan. Nama-nama permainannya adalah bancakan (A), barén, éngklé gunung, galah, kakalécian, ucing buaya, ucing jongkok, ucing sumput (A), ucing tépa, bancakan (B), éngklé biasa, ngadu keléréng, om-oman, ucing jatup, babancakan, bébélotan, dodo-dodoan, éngklé kapal, pocés, ucing sendal (A), ucing sumput (B), congkak, ééngkléan, ngadu kaléci, lompat karét, sasapintrongan, ucing babuk, sarta ucing sendal (B). Dalam permainannya, setiap permainan dibagi menjadi tiga tahapan, yaitu (1) persiapan, (2) mulai main, dan (3) selesai bermain. Dari tahapan-tahapan permainannya dianalisis nilai-nilai entopedagogik yang terdapat dalam permainan tersebut. Berdasarkan hasil penelitian, terdapat empat nilai moral yang ditemukan dalam setiap permainan, yaitu moral manusa ka dirina, moral manusa ka manusa, moral manusa ka alam, sarta moral manusa dina ngahontal kasugemaan lahir batin. Berdasarkan analisis hasil penelitian, terdapat 12 karakter bangsa yang ditemukan, yaitu jujur, toleransi, disiplin, kerja keras, kreatif, mandiri, demokratis, menghargai prestasi, bersahabat/komunikatif, cinta damai, peduli lingkungan, sarta tanggung jawab.
\end{abstract}

Kata kunci: permainan anak-anak, struktural, etnopedagogik

\section{TRADITIONAL CHILDREN'S GAMES IN CONGGEANG DISTRICTS, SUMEDANG REGENCY (The Study of Stucture and Ethnopedagogy)}

\begin{abstract}
This paper discusses the children's games in Conggeang District, Sumedang Regency, based on structural and ethnopedagogical perspectives. The traditional children's games are now already becoming obsolete because of modern games. The method used in this research was descriptive method. The data collection method in this research was observation, interview, literature study, and documentation. The research found 28 games. The names of the games are bancakan (A), barén, éngklé gunung, galah, kakalécian, ucing buaya, ucing jongkok, ucing sumput (A), ucing tépa, bancakan (B), éngklé biasa, ngadu keléréng, om-oman, ucing jatup, babancakan, bébélotan, dodo-dodoan, éngklé kapal, pocés, ucing sendal (A), ucing sumput (B), congkak, ééngkléan, ngadu kaléci, lompat karét, sasapintrongan, ucing babuk, and ucing sendal (B). Each game is divided into three stages: (1) the preparation, (2) the game, and (3) the completion. Based on the stages of the games, there are ethnopedagogical values in the game. The study revealed four moral values found in every game, namely moral
\end{abstract}


manusa ka dirina, moral manusa ka manusa, moral manusa ka alam, sarta moral manusa dina ngahontal kasugemaan lahir batin. The study also found 12 characters of nation covering honesty, tolerance, discipline, hard work, creative, independent, democratic, recognizing excellence, friendship/communicative, peace-loving, caring environment, and responsibility.

Keywords: Traditional Children's Games, Structure, ethnopedagogy

\section{PENDAHULUAN}

Seiring dengan kemajuan jaman. Sekarang ini banyak tradisi yang sudah mulai mati, baik itu disebabkan oleh tidak dikenal lagi maupun karena sulit atau tidak adanya sarana agar tetap hidup. Salah satu tradisi atau hasil budaya yang memperlihatkan kematiannya adalah permainan anak-anak tradisional. Hal ini terlihat oleh jarangnya anak-anak memainkan permainan tradisional. Permainan anak-anak sudah mulai ditinggalkan karena tergerus oleh permainan-permainan modern seperti HP, internet, PS, dan lain sebagainya.

Sebelum permainan modern datang, anak kecil di wilayah Sunda mempunyai berbagai macam permainan untuk mengisi waktu bermain mereka sesudah belajar atau sesudah membantu orang tua. Permainan anak-anak merupakan kesenian yang sering dilakukan oleh anak-anak di waktu santai (Su.m.wikipedia.org).

Permainan anak-anak mempunyai beberapa ciri yang merupakan ciri tradisi lisan, diantaranya adalah (1) kebiasaan yang bentuknya lisan, sebagian lisan, serta bukan lisan, (2) mempunyai peristiwa atau kegiatan sebagai konteksnya, (3) bisa diperhatikan serta ditonton, (4) sifatnya tradisional, (5) diwariskan secara turuntemurun, (6) proses menyampaikannya oleh media lisan atau "dari mulut ke telinga", (7) di dalamnya terdapat nilai-nilai budaya sebagai kearifan lokal, (8) mempunyai versi atau variasi, (9) ada potensi untuk direvitalisasi serta diangkat secara kreatif sebagai sumber industry budaya, serta (10) dimiliki oleh komunitas tertentu (Sibarani, 2012, hal. 123-124). Melihat ciri-ciri permainan anak-anak, ada beberapa hal yang bisa digali, diantaranya adalah nilai- nilai budaya yang ada dalam permainan serta potensi revitalisasi agar permainan anak-anak bisa hidup lestari di masyarakat.

Nilai-nilai budaya yang bisa digali dan sesuai dengan kemekaran jaman adalah nilai pendidikan yang merupakan bagian dari etnopedagogik. Alwasilah (2009, hal. 50) menyatakan bahwa etnopedagogik merupakan praktek pendidikan yang berbasis kearifan lokal dalam berbagai hal. Berbagai hal tersebut bisa mencakup cara mengobati macam-macam penyakit, seni bela diri, lingkungan hidup, sistem pertanian, ekonomi, pemerintahan, sistem perhitungan bintang, dan sebagainya.

Permainan anak-anak bisa mendidik atau menularkan nilai pendidikan yang terdapat dalam permainan. Anak-anak bisa menerima nilai-nilai pendidikan secara sukarela. Hal ini sesuai dengan pembahasan Déwantara (1962, hal 248) yang menyatakan bahwa:

"Patut diingat pula, bahwa didikan jang terdapat dalam permainan kanak-kanak itu diterima oleh kanakkanan tidak dengan paksaan atau perintah, akan tetapi karena kemauan serta kesenangan anak-anak sendiri untuk menerima dan mengalami segala pengaruh jang sangat pedagogis itu."

Dengan semakin hilangnya permainan anak-anak, dikhawatirkan akan adanya keunduran karakter anak-anak. Yang dikarenakan oleh tidak dilatihnya serta tidak dididik secara alami tanpa adanya paksaan. Hal ini sudah mulai terlihat, diantaranya anak-anak jaman sekarang sudah semakin menurun kesopanannya. Serta sikap sosial anak-anak yang semakin hilang, yang lebih 
muncul pada saat ini adalah sikap individualis yang dikarenakan pengaruh permainan-permainan modern. Selain dari pengaruh permainan modern, hilangnya permainan anak-anak tradisional terpengaruh oleh kurangnya kepedulian orang tua terhadap pentingnya permainan anakanak dalam membangun karakter anak. Sekarang ini banyak anggapan bahwa anakanak lebih baik diam di rumah sembari memainkan computer, PS, dan yang lainnya, dari pada main di luar. Tidak pedulinya orang tua terhadap pentingnya permainan anak-anak bisa disebabkan oleh ketidak pahaman terhadap nilai-nilai yang terdapat dala permainan anak-anak.

Sebelum menemukan etnopedagogik yang terdapat dalam perminan anak-anak, harus dilakukan dulu pengumpulan (inventarisir) permainan yang akan diteliti. Pengumpulan data permainan anak-anak dilaksanakan di Kecamatan Conggeang Kabupaten Sumedang. Dipilihnya Kecamatan Conggeang karena kecamatan ini terbilang pelosok, jauh dari pusat kota. Jadi, diharapkan masih banyak permainan anakanak yang hidup di daerah ini.

Setelah dikumpulkan permainan-permainan yang terdapat di daerah Kecamatan Conggeang, lalu dianalisis struktur permainannya untuk memudahkan dalam menginterpretasikan atau mencari nilai-nilai etnopedagogik yang terdapat dalam permainan tersebut.

Agar tidak terlalu luas cakupannya, penelitian ini dibatasi hanya sebatas mendeskripsikan struktur permainan anakanak yang mencakup (1) nama permainan, (2) waktu, (3) tempat, (4) pelaku yang mencakup jumlah, umur, dan jenis kelamin, (5) peralatan, serta (6) proses bermain yang mencakup proses persiapan, melaksanakan permainan, dan selesai bermain. Dari struktur permaian yang ditemukan, seterusnya digali nilai etnopedagogik yang merupakan nilai oral yang berdasarkan pada konsep Warnaen, serta 18 nilai karakter bangsa. Nilai moral mencakup (1) moral manusa ka pangéran, (2) moral manusa ka dirina, (3) moral manusa ka manusa, (4) moral manusa ka alam, (5) moral manusa ka waktu, sarta (6) moral manusa dina ngahontal kasugemaan lahir batin. Nilai karakter bangsa mencakup (1) religious, (2) jujur, (3) toleransi, (4) disiplin, (5) kerja keras, (6) kreatif, (7) mandiri, (8) demokratis, (9) rasa ingin tahu, (10) semangat kebangsaan, (11) cinta tanah air, (12) menghargai prestasi, (13) bersahabat/ komunikatif, (14) cinta damai, (15) gemar membaca, (16) peduli lingkungan, (17) peduli sosial, sarta (18) tanggung jawab.

Setelah menganalisis struktur dan menggali nilai-nilai etnopedagogik yang terdapat dalam permainan anak-anak, lalu menentukan fungsi dari permainan tersebut.

\section{METODE}

Metode yang digunakan dalam penelitian ini adalah metode deskriptif. Yang dimaksud metode deskriptif adalah metode yang bisa menyelesaikan permasalahan secara actual dengan cara mengumpulkan, menyusun, mengelompokkan, menganalisis, dan menafsirkan (Surakhmad, 1994, hal. 139).

Metode deskriptif digunakan dalam penelitian ini untuk mendeskripsikan struktur permainan dan nilai-nilai etnopedagogik yang terdapat dalam permainan anak-anak, baik itu nilai yang merupakan nilai moral manusia maupun nilai karakter bangsa.

Sumber data yang dipakai dalam penelitian ini adalah masyarakat atau perilaku anak-anak dalam melaksanakan permainan anak-anak. Sumber datanya adalah anak-anak yang ada di daerah Kecamatan Conggeang. Penelitian ini menggunakan sampel, karena tidak semua wilayah Kecamatan Conggeang diambil sebagai datanya. Sampelnya adalah anak-anak yang berada di beberapa desa yang berada di Kecamatan Conggeang.

Dalam menentukan sampel dilakukan dengan cara sampel wilayah. Sampel wilayah adalah teknik sampling yang dilakukan dengan cara mengambil wakil 
dari setiap wilayah yang terdapat dalam populasi (Arikunto, 2010, kc. 182).

Oleh karena itu, data dalam penelitian ini diambil dari 5 desa yang ditentukan berdasarkan wilayah arah mata angin. Kelima desa tersebut adalah Desa Ungkal, Desa Babakan Asem, Desa Cibubuan, Desa Narimbang, dan Desa Conggeang Wetan.

\section{PETA KECAMATAN CONGGEANG}

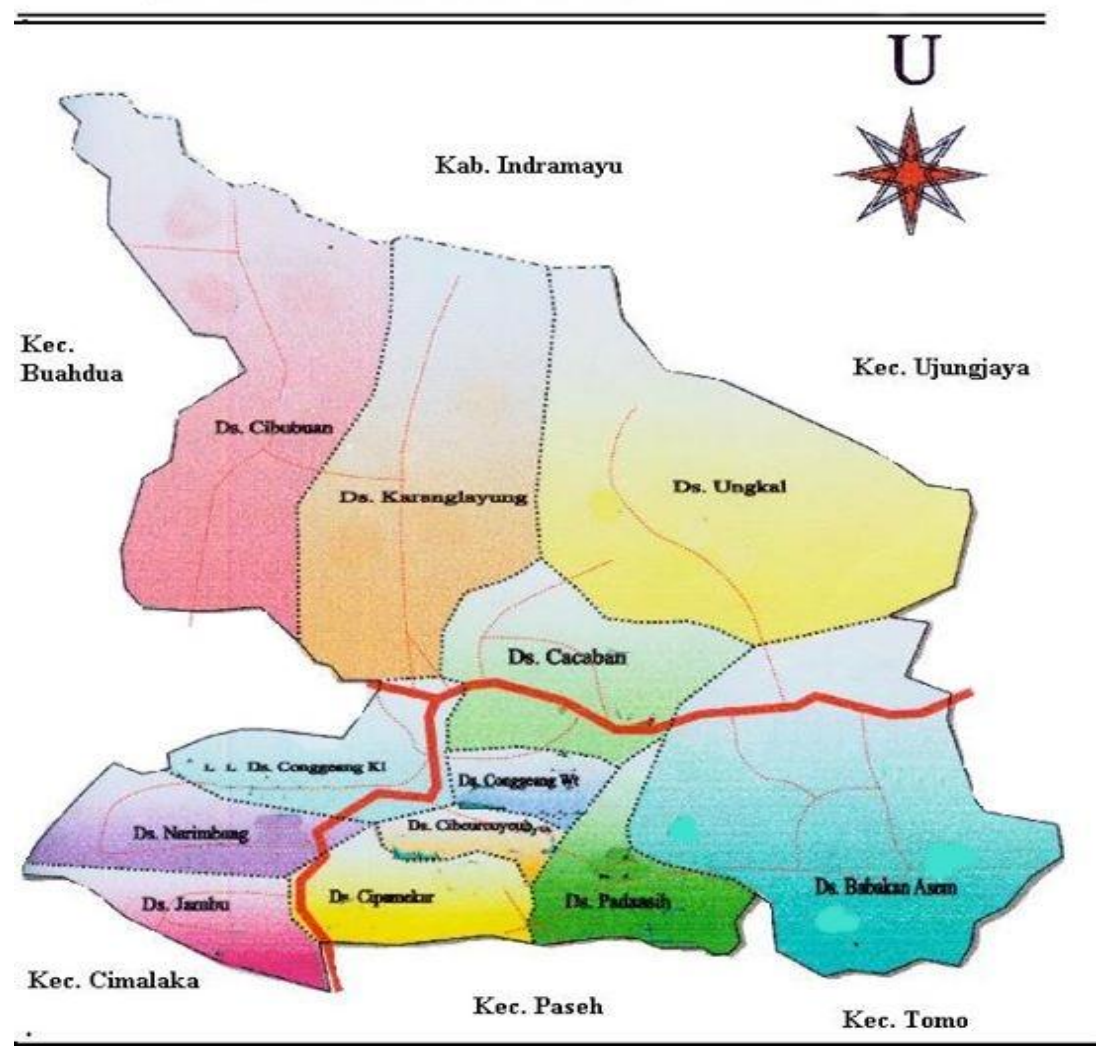

KETERANGAN :

- - : Batas Kabupaten

- : Batas Wilayah Kecamatan

......... : Batas Wilayah Desa

: Jalan Kabupaten

: Jalan Desa

\section{HASIL DAN PEMBAHASAN}

Dalam Kamus Basa Sunda R.A. Danadibrata (2006, kc. 725) dijelaskan bahwa kaulinan nya éta sagala anu sok dibawa, dipaké ulin, cocooan, kaulinan barudak. Sedangkan LBSS (1995, kc. 243) menjelaskan

"kaulinan asal kecap tina ulin anu hartina nyangkem haté keur udarider atawa ngalampahkeun perkara anu matak resep sorangan atawa jeung babaturan. Anapon kaulinan nya éta perkara nu sok dipaké ulin, kaheureuyan, saperti ucing-ucingan, galah, $j$ st."

Permainan merupakan sebuah aktivitas rekreasi dengan tujuan bersenang-senang, mengisi waktu luang, atau berolahraga ringan. Permainan biasanya dilakukan sendiri atau bersama-sama. Banyak permainan yang dilakukan oleh anak-anak secara beramai-ramai dengan teman-teman mereka di halaman atau di teras rumah. Mereka berkelompok, berlarian, atau duduk melingkar memainkan salah satu permainan 
dan tercipta keakraban. (Hidayat, kc. 2013, kc. 1060).

Barudak berasal dari kata budak yang artinya anak perempuan atau anak laki-laki yang belum balig (Danadibrata. 2006, hal. 107). Jadi kesimpulannya, kaulinan barudak adalah segala hal yang dipakai oleh anak-anak yang membuat senang yang selalu dimainkan oleh sendiri atau bersamasama dengan teman-temannya, seperti ucing-ucingan, galah, dan lain sebagainya.

Dari hasil penelitian ditemukan 28 permainan. Nama-nama permainannya adalah bancakan (A), barén, éngklé gunung, galah, kakalécian, ucing buaya, ucing jongkok, ucing sumput (A), ucing tépa, bancakan (B), éngklé biasa, ngadu keléréng, om-oman, ucing jatup, babancakan, bébélotan, dodo-dodoan, éngklé kapal, pocés, ucing sendal (A), ucing sumput (B), congkak, ééngkléan, ngadu kaléci, lompat karét, sasapintrongan, ucing babuk, sarta ucing sendal (B).

Jumlah ermainan yang diperoleh dari stiap desa berbeda-beda dari 28 permainan, ditemukan ada 25 nama permainan. Ada 3 nama permainan yang terdapat di dua desa sekaligus, itu adalah (1) bancakan, (2) ucing sendal, dan (3) ucing sumput.

Walaupun namanya sama, tapi dalam proses bermainnya berbeda. Oleh karena itu, walau ada 25 nama permainan, tetapi yang dianalisis berjulah 28 permainan, sesuai dengan data yang diperoleh.

Unsur yang dianalisis dari struktur dalam kaulinan barudak

1. Ngaran Kaulinan

2. Waktu

3. Tempat

4. Pelaku / Pamaén
a. Jumlah
b. Umur
c. Wanda jinis

5. Kelengkapan kaulinan

6. Persiapan kaulinan
a. Tatahar
b. Prung arulin
c. Réngsé arulin

\section{SIMPULAN}

Simpulan dari penelitian ini adalah hasil penelitiannya bisa digunakan sebagai bahan pemelajaran. Dengan adanya penelitian ini diharapkan bisa merubah pola fikir bahwa mendidik siswa tidak harus selalu dalam keadaan serius dan formal di dalam kelas. Tapi, bisa sambil bermain. Sesuai dengan konsep Ki Hajar Déwantara yang menyebutkan siswa secara tidak langsung bisa menerima nilai pendidikan dari hal-hal yang tidak selalu formal (belajar sambil bermain). Penelitian ini bisa menumbuhkan kemajuan kaulinan-kaulinan barudak tradisional yang kini hampir ditinggalkan.

\section{PUSTAKA RUJUKAN}

Alwasilah, Chaedar spk. 2009. Etnopedagogi (landasan Praktek Pendidikan dan Pendidikan Guru). Bandung: Kiblat Buku

Arikunto, Suharsimi. 2010. Prosedur Penelitian Sebuah Pendekatan Praktik. Jakarta: PT. Rineka Cipta.

Danadibrata. 2006. Kamus Basa Sunda. Bandung: PT. Kiblat Buku Utama.

Dewanrata, Ki Hajar. 1962. Karja Ki Hajar Dewantara Bagian Pertama:

Pendidikan. Jogjakarta: Pertjetakan Taman Siswa.

Hidayat, Dasrun. 2013. Permainan Tradisional dan Kearifan Lokal Kampung Dukuh Garut Selatan Jawa Barat. [Artikel]. http://jurnal. untad.ac.id/jurnal/index.php/academica /article/download/2244/1448. Diaksés ping 04 Désémber 2014.

Kaulinan Budak. [Artikel]. http://su.m.wikipedia.org/wiki/Kaulina n_budak. Diaksés ping 04 Désémber 2014

LBSS. 1995. Kamus Umum Basa Sunda. Bandung: Tarate Bandung.

Sibarani, Robert. Kearifan Lokal. Hakikat, Peran, dan Métode Tradisi Lisan. 2012. Jakarta: Asosiasi Tradisi Lisan.

Surakhmad. 1994. Pengantar Penelitian Ilmiah. Bandung: Tarsito. 


\section{UCAPAN TERIMA KASIH}

Kepada pembimbing tesis yang telah membantu penelitian ini penulis mengucapkan terima kasih. Tidak luput pula ucapan terima kasih dan penghargaan setinggi-tingginya penulis sampaikan kepada penyunting Jurnal Lokabasa yang telah memuat tulisan ini. 